\title{
Approximation of zeros of $m$-accretive mappings, with applications to Hammerstein integral equations
}

\section{E. Chidume ${ }^{1}$, G. S. DE SOUZA ${ }^{2}$, U. V. NnyABA ${ }^{1}$, O. M. RomAnus ${ }^{1}$ and A. $\mathrm{ADAMU}^{1}$}

\begin{abstract}
.
An algorithm for approximating zeros of $m$-accretive operators is constructed in a uniformly smooth real Banach space. The sequence generated by the algorithm is proved to converge strongly to a zero of an $m$ accretive operator. In the case of a real Hilbert space, our theorem complements the celebrated proximal point algorithm of Martinet and Rockafellar for approximating zeros of maximal monotone operators. Furthermore, the convergence theorem proved is applied to approximate a solution of a Hammerstein integral equation. Finally, numerical experiments are presented to illustrate the convergence of our algorithm.
\end{abstract}

Acknowledgements. The authors appreciate the support of their institute and the African Development Bank (AfDB) for the Research Grant that enable this work to be carried out. The authors wish to thank the referees for their esteemed comments and suggestions.

\section{REFERENCES}

[1] Barbu, V., Analysis and control of nonlinear infinite dimensional systems, p. cm. Mathematics in science and engineering, v.189, ISBN 0-12-078145-X

[2] Berinde, V., Iterative Approximation of Fixed points, Lecture Notes in Mathematics, Springer, London, UK, (2007)

[3] Bruck, B., Matouskov, E. and Reich, S., Projection and Proximal Point Methods: convergence results and counterexamples, Nonlinear Anal., 56 (2004), 715-738

[4] Brézis, H. and Browder, F. E., Nonlinear integral equations and systems of Hammerstein type, Advances in Math., 18 (1975), No. 2, 115-147

[5] Browder, F., Nonlinear monotone operators and convex sets in Banach spaces, Bull. Amer. Math. Soc., 71 (1965), 780-785

[6] Browder, F. E., De Figueiredo, D. G. and Gupta, C. P., Maximal monotone operators and nonlinear integral equations of Hammerstein type, Bull. Amer. Math. Soc., 76 (1970) 700-705

[7] Browder, F. E. and Gupta, C. P., Monotone operators and nonlinear integral equations of Hammerstein type, Bull. Amer. Math. Soc., 75 (1969), 1347-1353

[8] Bruck, R. E., A strong convergent iterative solution of $0 \in U(x)$ for a maximal monotone operator $U$ in Hilbert space, J. Math. Anal. Appl., 48 (1974), 114-126

[9] Bruck, R. E. and Reich, S., Nonexpansive projections and resolvents of accretive operators in Banach spaces, Houston J. Math., 3 (1977), 459-470

[10] Chepanovich, R. Sh., Nonlinear Hammerstein equations and fixed points, Publ. Inst. Math. (Beograd) N. S., 35 (1984), 119-123

Received: 21.08.2019; In revised form: 27.01.2020; Accepted: 04.02.2020

2010 Mathematics Subject Classification. 47H09, 47H10, 47J25 47J05, 47J20.

Key words and phrases. Fixed points, pseudocontractive mapping, accretive mapping, strong convergence.

Corresponding author: C. E. Chidume; cchidume@aust.edu.ng 
[11] Chidume, C. E., Geometric Properties of Banach Spaces and Nonlinear Iterations, Lecture Notes in Mathematics, 1965 Springer, London (2009)

[12] Chidume, C. E., Strong convergence theorems for bounded accretive operators in uniformly smooth Banach spaces, Nonlinear analysis and optimization, 31-41, Contemp. Math., 659, Amer. Math. Soc., Providence, RI, 2016

[13] Chidume, C. E., The iterative solution of the equation $f \in x+T x$ for a monotone operator $T$ in $L^{p}$ spaces, J. Math. Anal., 116 (1986), No. 2, 531-537

[14] Chidume, C. E., Adamu, A., Minjibir, M. S. and Nnyaba, U. V., On the strong convergence of the proximal point algorithm and applications (to appear)

[15] Chidume, C. E. and Zegeye, H., Approximation of solutions of nonlinear equations of Hammerstein type in Hilbert space, Proc. Amer. Math. Soc., 133 (2005), No. 3, 851-858

[16] Chidume, C. E. and Zegeye, H., Approximation of solutions of nonlinear equations of monotone and Hammerstein type, Appl. Anal., 82 (2003), No. 8, 747-758

[17] Chidume, C. E. and Djitte, N., Approximation of solutions of nonlinear integral equations of Hammerstein type, ISRN Math. Anal., 12 (2012) 169751, doi: 10.5402/2012/169751

[18] Chidume, C. E. and Idu, K. O., Approximation of zeros of bounded maximal monotone mappings, solutions of Hammerstein integral equations and convex minimization problems, Fixed Point Theory and Appl., (2016) 2016:97, DOI 10.1186/s13663-016-0582-8.

[19] Chidume, C. E. and Bello, A. U., An iterative algorithm for approximating solutions of Hammerstein equations with monotone maps in Banach spaces, Appl. Math. Comput., 313 (2017), 408-417

[20] Chidume, C. E. and Shehu, Y., Iterative approximation of solutions of equations of Hammerstein type in certain Banach spaces, Applied Math. and Comp., 219 (2013), 5657-5667

[21] Chidume, C. E., Nnakwe, M. O. and Adamu, A., A strong convergence theorem for generalized- $\Phi$-strongly monotone maps, with applications, Fixed Point Theory and Appl., (2019), https://doi.org/10.1186/s13663019-0660-9

[22] Chidume, C. E., Adamu, A., and Chinwendu, L. O., Approximation of solutions of Hammerstein equations with monotone mappings in real Banach spaces, Carpathian J. Math., 35 (2019), No. 3, 305-316

[23] De Figueiredo, D. G. and Gupta, C. P., On the variational methods for the existence of solutions to nonlinear equations of Hammerstein type, Bull. Amer. Math. Soc., 40 (1973), 470-476

[24] Dolezale, V., Monotone Operators and its Applications in Automation and Network Theory, Studies in Automation and Control, (Elsevier Science Publ.) New York, 1979

[25] Djitte, N, and Sene, M., Iterative solution of nonlinear integral equations of Hammerstein type with Lipschitz and accretive operators, ISRN Appl. Math., (2012), Article ID 963802, 15 pages, DOI:5402/2012/963802

[26] Fitzpatrick, P. M., Hess, P. and Kato, T., Local boundedness of monotone type operators, Proc. Japan Acad., 48 (1972), 275-277

[27] Güler, O., On the convergence of the proximal point algorithm for convex minimization, SIAM J. Control Optim., 29 (1991), 403-419

[28] Kamimura, S. and Takahashi, W., Strong convergence of a proximal-type algorithm in a Banach space, SIAMJ. Optim., 13 (2002), No. 3, 938-945

[29] Kato, T., Nonlinear semigroups and evolution equations, J. Math. Soc. Japan, 19 (1967), 511-520

[30] Kirk, W. A., A fixed point theorem for mappings which do not increase distance, Amer. Math. Monthly, 72 (1965), 1004-1006

[31] Kirk, W. A., Remarks on pseudo-contractive mappings, Proc. Amer. Math. Soc., 25 (1970), 820-823

[32] Lehdili, N. and Moudafi, A., Combining the proximal algorithm and Tikhonov regularization, Optimization, 37 (1996), 239-252

[33] Mann, W. R. Mean value methods in iteration, Proc. Amer. Math. Soc., vol. 4 (1953), pp. 506-510.

[34] Martinet, B., Régularisation ďinéquations variationnelles par approximations successives, Revue française dinformatique et de Recherche Opérationnelle, 4 (1970), 154-158

[35] Ofoedu, E. U. and Onyi, C. E., New implicit and explicit approximation methods for solutions of integral equations of Hammerstein type, Appl. Math. Comput., 246 (2014), 628-637

[36] Pascali, D. and Sburian, S., Nonlinear mappings of monotone type, Editura Academia Bucureşti, România, 1978

[37] Reich, S., Constructive techniques for accretive and monotone operators, Applied non-linear analysis, Academic Press, New York (1979), 335-345

[38] Reich, S., Extension problems for accretive sets in Banach spaces, J. Functional Anal., 26 (1977), 378-395

[39] Reich, S., Iterative methods for accretive sets in Banach Spaces, Academic Press, New York, 1978, 317-326 
[40] Reich, S. and Sabach, S., Two strong convergence theorems for a proximal method in reflexive Banach spaces, Numer. Funct. Anal. Optim., 31 (2010), No. 1-3, 22-44

[41] Rockafellar, R. T., Monotone operators and the proximal point algorithm, SIAM J. Control Optim., 14 (1976), No. $5,877-898$

[42] Rockafellar, R. T., On the maximality of sums of nonlinear monotone operators, Trans. Amer. Math. Soc., 149 (1970), 75-88

[43] Shehu, Y., Strong convergence theorem for integral equations of Hammerstein type in Hilbert spaces, Appl. Math. Comput., 231 (2014), 140-147

[44] Solodov, M. V. and Svaiter, B. F., Forcing strong convergence of proximal point iterations in a Hilbert space, Math. Program., 87 (2000), No. 1, Ser. A, 189-202

[45] Xu, H. K., A regularization method for the proximal point algorithm, J. Global Optim., 36 (2006), No. 1, 115125

[46] Xu, Z. B. and Roach, G. F., Characteristic inequalities of uniformly convex and uniformly smooth Banach space, J. Math. Anal. Appl., 157 (1991), No. 1, 189-210

[47] Zeidler, E., Nonlinear Functional Analysis and Its application III: Variational Methods and Optimization, Springer Berlin (1985), Translated from the German by Leo F. Boron

${ }^{1}$ African University of Science And Technology, Abuja, KM 10 AIRPORT ROAD, FCT, GALADIMAWA, NIGERIA

Email address: cchidume@aust.edu.ng

Email address: nukamaka@aust.edu.ng

Email address: rromanuseaust.edu.ng

Email address: aadamu@aust.edu.ng

2 Auburn University, Department of Mathematics and Statistics, AUBURN AL 336849-5310-USA

Email address: desougs @auburn.edu 